\title{
PAULO FREIRE: DO (RE)EXÍLIO BRASILEIRO ÀS CATEDRAS NORTE-AMERICANAS
}

\author{
PAULO FREIRE FROM THE BRAZILIAN (RE) EXILE TO THE NORTH \\ AMERICAN CATHEDRAS
} PAULO FREIRE DEL (RE)EXÍLIO BRASILEÑO A LAS CATEDRAS
NORTE AMERICANAS

Walmir Marcolino Gomes*

(iD) https://orcid.org/oooo-0001-7018-8457

Antônio José Muller**

https://orcid.org/oooo-0oo3-3772-331X

\begin{abstract}
REVISTA PEDAGÓGICA
Revista do Programa de Pós-graduação em Educação da Unochapecó | ISSN 1984-1566 Universidade Comunitária da Região de Chapecó | Chapecó-SC, Brasil Como referenciar este artigo: GOMES, W. M.; MULLER, A. J. Paulo Freire: do (re)exílio brasileiro às catedras norte-americanas. Revista Pedagógica, Chapecó, v. 21, p. 395-412, 2019. DOI: http://dx.doi.org/10.22196/rp.v22io.4878
\end{abstract}

\begin{abstract}
RESUMO: Paulo Freire é considerado o mais importante educador do final do século XX no mundo e sua obra é estudada e apresentada em inúmeras pesquisas de importância. Contudo, em seu próprio Brasil, sua obra vem sendo questionada pelo governo atual. Assim, no primeiro momento, este artigo apresenta o legado freireano no Brasil com as devidas ameaças políticas contemporâneas, para depois apresentar a importância de Freire nos EUA, em especial na Universidade da Califórnia em Los Angeles, e sua presença no programa de Pós-Graduação em Educação da referida instituição, primeira colocada no ranking de programas de PósGraduação em Educação dos EUA. Por meio deste artigo, busca-se promover uma problematização crítica acerca da desvalorização de Freire no momento atual no Brasil, contrabalanceando com a inerente relevância de Freire nos EUA.
\end{abstract}

Palavras-chave: Paulo Freire. Educação no Brasil. Educação nos EUA.

ABSTRACT: Paulo Freire is considered the most important educator of the late twentieth century in the world and his work is studied and presented in countless important researches. However, in his own Brazil, his work has been questioned by the current government. Thus, in the first moment, this article presents the Freirean legacy in Brazil, with the appropriate contemporary political threats. After will present the importance of Freire in the USA, especially at the University of California in Los Angeles, and his presence in the Post-Graduated in Education from this institution, first placed in the ranking of programs in the Post-Graduated in Education of the USA. The objective of this article is to promote a critique of Freire's devaluation at this present moment in Brazil, counterbalancing with the inherent relevance of Freire in the USA.

Keywords: Paulo Freire. Education in Brazil. Education in the USA.

RESUMEN: Paulo Freire es considerado el más importante educador del final del siglo XX en el mundo y su obra es estudiada y presentada en innumerables investigaciones de importancia. Sin embargo, en su propio Brasil, su obra viene siendo cuestionada por el gobierno actual. En el primer momento, este artículo presenta el legado freireano en Brasil, con las debidas amenazas políticas contemporáneas, para luego presentar la importancia de Freire en los Estados Unidos, en especial en la Universidad de California en Los Ángeles, y su presencia en el programa de Post-Graduación en Educación de esta institución, primera colocada en el ranking de programas Post-Graduación en Educación de los Estados Unidos. El objetivo de este artículo es promover una crítica de la desvalorización de Freire en el momento actual en Brasil, contrarrestando con la inherente relevancia de Freire en los Estados Unidos.

Palabras clave: Paulo Freire. Educación en Brasil. Educación en los Estados Unidos. 


\section{1 introdução}

Paulo Freire (1921-1997), nascido no nordeste brasileiro, foi um dos mais conhecidos e influentes teóricos da educação no século XX. Seu impacto sobre a educação para a paz, educação de adultos, educação não formal e alfabetização crítica tem sido incalculável (BARTLETT, 2008). Sua obra continua a provocar novas teorias e extrapola barreiras regionais e culturais, e vem sendo utilizada em diversos países por meio de pesquisas na área das ciências humanas. Suas ideias se difundiram internacionalmente, resultando na reedição de sua obra em várias partes do mundo. Conforme relembra Saul (2016, p. 11),

[...] seu livro mais importante, Pedagogia do Oprimido, foi traduzido em mais de vinte idiomas. A Pedagogia da Autonomia, seu último livro publicado enquanto vivia, já ultrapassou a marca de um milhão de exemplares. Tal projeção confere ao conjunto de suas produções o caráter de uma obra universal que se destaca na literatura educacional, nos depoimentos de importantes autores, em diferentes países, no reconhecimento de seu trabalho por importantes Universidades do mundo e no crescente número de pesquisas que se apoiam no referencial de Freire.

De acordo com Veiga (2019), Freire é estudado em universidades americanas, foi homenageado com escultura na Suécia, com nome de centro de estudos na Finlândia e inspiração para cientistas em Kosovo. Há instituições de ensino que seguem o método Paulo Freire em diversos países. É o caso da Revere High School, escola em Massachusetts, que em 2014 foi avaliada como a melhor instituição pública de ensino médio nos Estados Unidos (VEIGA, 2019).

Freire é presença marcante nos cursos de formação de professores das melhores universidades do mundo. Existem anualmente conferências e seminários para promover os pensamentos freireanos no Canadá, na Alemanha, na Coreia do Sul, na Austrália, no Chile, na África do Sul, na Finlândia, entre outros países onde a educação é prioridade. Ainda, de acordo com o Instituto Paulo Freire (2019), existem países onde há Institutos Paulo Freire (constituídos ou em formação) na África do Sul (Cidade do Cabo), Alemanha (Berlim e Munique), Argentina (Buenos Aires, IPF-Chacabuco, Rosário, Tandil), Canadá (Toronto), Coreia, Chile (Santiago), China (Hong Kong), Colômbia (Bogotá), Egito, Espanha (Valência), Estados Unidos (Los Angeles), Grécia (Tessalónica), Guiné-Bissau (Bissau), Índia (Calcutá e Mumbai), Israel (Mazkeret Batia e Jerusalém), Itália (Bolonha e Milão), Malta, México (Hermosillo), Porto Rico, Portugal (Cidade do Porto), Reino Unido (Manchester), República Dominicana, Suécia.

\begin{abstract}
* Mestrando em educação pela universidade de Blumenau - FURB. Membro do grupo de pesquisa Educogitans da FURB (filosofia e educação). Especialização em ética pela Pontifícia Universidade Católica do Paraná - PUCPR. Bacharel em teologia pela Pontifícia Universidade Católica do Paraná - PUCPR. Licenciado em filosofia pela rede Claretiano de Educação.

E-mail:padrewalmir@gmail.com

** Doutor em Educação - Liderança e Administração Educacional - pela The University of Texas at El Paso (2004). Atualmente é professor titular da FURB (Universidade Regional de Blumenau) no Programa de Pós Graduação em Educação (Mestrado em Educação) e Departamento de Educação Física e faz parte do Grupo de Pesquisa em Filosofia e Educação - EDUCOGITANS da FURB. Trabalhou como docente da graduação presencial e coordenou os programas de pesquisa e extensão do núcleo de ensino a distância e foi coordenador do curso de educação física da Uniasselvi em Santa Catarina, professor de ensino superior em nível de graduação e pós-graduação no Brasil, EUA e Arábia Saudita. Ex- Diretor Pedagógico do Colégio Energia Blumenau e Diretor de Instrução da Paso Del Norte Academy (Charter School) em El Paso-EUA. Especialista em Paulo Freire e com larga experiência na área de Educação e Esporte, com ênfase em Educação de Professores. E-mail: antoniomuller2@hotmail.com
\end{abstract}


Freire é reconhecido ainda por desenvolver o método de alfabetização de adultos utilizado em diversas regiões do mundo. O "método Paulo Freire" - lembrando que o próprio Paulo Freire entendia tratar-se muito mais de uma teoria do conhecimento do que de uma metodologia de ensino -, muito mais um método de aprender que um método de ensinar (FEITOSA; GADOTTI, 1999) e que seguia princípios ancorados em uma filosofia/pedagogia -, estimula a alfabetização dos adultos mediante a discussão de seus conhecimentos cotidianos, através de palavras presentes na realidade dos alunos, chamadas de palavras ou temas geradores que são entendidas para a aquisição da palavra escrita e da compreensão do mundo (BECK, 2016). Assim, Freire enfatizou a alfabetização crítica em oposição à alfabetização funcional.

Entre estas e outras contribuições, Freire é um dos principais autores quando se discute a formação de professores. Para Gadotti (2007), "Pedagogia da Autonomia" é o livro mais importante de Paulo Freire sobre o professor e sua formação, o qual mostra o quanto a formação do professor é importante para qualquer mudança educacional, sobretudo para a melhoria da qualidade do ensino. O livro é direcionado àqueles que trabalham a educação com respeito ao conhecimento dos alunos, estimulado a partir da dialogicidade entre educador e educando, como explica Freire (2011a, p. 25):

Não há docência sem discência, as duas se explicam e seus sujeitos, apesar das diferenças que os conotam, não se reduzem à condição de objeto, um do outro. Quem ensina aprende ao ensinar e quem aprende ensina ao aprender.

Freire também tem influência nos maiores pensadores atuais em educação e suas ideias estão presentes na produção acadêmica de Michel Apple, Henry Giroux, Peter McLaren, Enrique Dussel, Antonio Nóvoa e Licínio Lima (SANTIAGO; BATISTA NETO, 2016).

Neste sentido, a intenção deste texto é apresentar a presença de Freire na política e educação do Brasil da atualidade. Ainda, como uma provocação, iremos apresentar a importância de Freire nos Estados Unidos, em particular nos cursos de formação de professores e diretores do Centro de Educação da Universidade da Califórnia em Los Angeles (University of California at Los Angeles - UCLA), que, de acordo com a publicação US News and World Report em 2018, foi considerada a melhor escola de Pós-Graduação em Educação dos EUA (UCLA, 2019a) e como referência em educação no mundo. Por intermédio de pesquisa bibliográfica, este texto irá apresentar opiniões de pensadores que corroboram com Freire nos EUA, em especial Peter McLaren. 


\section{Legado ameaçado de Paulo Freire no Brasil}

Incompreendido pela ditadura militar, Paulo Freire foi preso e exilado após o golpe de 1964, por desenvolver um programa de alfabetização para adultos entendido como uma forma de subversão:

Evidentemente, eu fui preso e exilado por causa da ditadura. A ditadura militar de 1964 não só considerou, mas disse por escrito e publicou que eu era um perigoso, subversivo internacional, um inimigo do povo brasileiro e um inimigo de Deus. (FREIRE, 1989 apud PINA, 2017, [s. p.])1.

Novamente há uma tentativa de (re)exílio de Paulo Freire pelo atual governo brasileiro, o filósofo tem sido constantemente criticado e atacado pelo presidente Jair Bolsonaro e sua equipe, sendo creditado a ele os persistentes problemas da educação no Brasil. No período da campanha eleitoral, o hoje presidente, já afirmava "vou entrar com um lança-chamas no MEC e tirar o Paulo Freire de lá de dentro" (CALÇADE, 2018, [s. p.]).

Nos primeiros dias de governo o presidente da república manifestou a intenção de "expurgar" a obra de Paulo Freire do sistema educacional e que tem sobre esta uma ideia de doutrinação ideológica, o que demonstra ignorância intelectual sobre Paulo Freire e seu legado. Maria Izabel Noronha, presidente da APEOESP ${ }^{2}$, afirmou à Folha de São Paulo:

Como professora, sinto-me no dever de começar com uma constatação: nem Bolsonaro, nem seus filhos e nem seu ministro da Educação leram a obra de Paulo Freire. Criticar algo sem sequer conhecer: isso sim é ideologia! E Bolsonaro tenta enganar a sociedade, afirmando querer "um país livre das amarras ideológicas". Se eventualmente leram a obra de Paulo Freire, não compreenderam nada. Se o fizessem, "livres das amarras ideológicas", poderiam formar um juízo mais isento. (NORONHA, 2019, [s. p.]).

Amigo do presidente Jair Bolsonaro, Olavo de Carvalho ${ }^{3}$ há muito tempo combate o pensamento freiriano e embasa a ideia de que Paulo Freire e seu pensamento foram e são prejudiciais à educação no Brasil. Em 2015, Carvalho publicou em sua rede social ${ }^{4}$ :

Paulo Freire, cujo maravilhoso sistema de ensino jamais produziu um escritor, um cientista, um filósofo ou mesmo um executivo competente, limitando-se a transformar milhares de coitadinhos em igual número de
1 Extraído da reportagem "Porque as ideias de Paulo Freire ainda incomodam?”, de 31 de outubro de 2017. 2 Sindicato dos Professores de São
Paulo. 3 Ensaísta, jornalista, astrólogo e
pensador brasileiro.

4 FACEBOOK, 30 de março de 2015. 
coitadinhos, é o patrono de uma educação nacional que produz analfabetos funcionais em massa e cujos estudantes obtêm sempre as piores notas nos testes internacionais. Se 41 universidades acham esse cidadão o máximo, 41 universidades deveriam ser fechadas.

Tais afirmações creditam a Paulo Freire a responsabilidade pela educação deficitária que constatamos hoje no Brasil. Pelas redes sociais, ecoa o apoio para que Paulo Freire e sua pedagogia sejam banidas das escolas. Contestam a sua obra sob acusação de doutrinação marxista, proselitismo político e ideias comunistas. Porém, os pressupostos freireanos não compõem o currículo da educação brasileira. E, além do mais:

Não há base empírica que comprove essas afirmações. Freire nunca foi comunista, ainda é mais lido nas universidades do exterior do que nas brasileiras, nunca pregou uma educação partidária nas escolas. Do mesmo modo, a crítica à qualidade literária de seus livros não se sustenta. Tais opiniões são proferidas por setores atrasados, que desrespeitam a pluralidade de ideias, sem compromisso com os ideais democráticos de liberdade de opinião. Não reconhecem no educador, tendo lido ou não as suas obras, concordando ou não com o seu pensamento, um interlocutor consagrado e respeitado. (HADDAD, 2019, [s. p.]) $)^{5}$.

Em uma dialética atual, na qual o conhecido se vela e o desconhecido se desvela, urge a necessidade de revelar o que já é conhecido, porém ignorado por alguns. Não se pode ignorar um legado reconhecido internacionalmente e desmerecido em sua terra natal. Nas palavras de Paulo Freire: "Ninguém ignora tudo. Ninguém sabe tudo. Todos nós sabemos alguma coisa. Todos nós ignoramos alguma coisa. Por isso aprendemos sempre" (FREIRE, 1989, p. 39).

Este (re)exílio de Paulo Freire está motivado por uma onda conservadora que permeia o mundo político e a própria educação no Brasil e na América Latina, inseminando um discurso de ódio e violência contra os movimentos sociais e os desfavorecidos, um afrontamento à democracia, atacando diretamente toda ação libertadora, social e popular que contrapõe os anseios de uma política direitista neoliberal de exploração, opressão e de desigualdades, sucumbindo o pensar crítico. E segundo Dennis de Oliveira (2017 apud PINA, 2017 [s. p.]):

Há toda uma ação de extrema direita conservadora muito forte e o campo da educação, nesta situação em que vivemos hoje, tem sido
5 Texto publicado no Jornal Folha de São Paulo, em 15 de abril de 2019. 
o campo em que ainda há resistência progressista. Uma parte dos meios de comunicação de massa, infelizmente, aderiu a essa visão golpista e direitista, enquanto na educação a gente ainda tem iniciativa de professores e educadores que tentam formar o pensamento crítico. ${ }^{6}$

Quando o conservadorismo atribui ao pensamento freireano o fracasso da educação brasileira, tornam-se atuais as palavras de Paulo Freire proferidas em 29 de maio de 1994, em uma entrevista ao Jornal Folha de São Paulo:

Em tese, o analfabetismo poderia ter sido erradicado com ou sem Paulo Freire. O que faltou foi decisão política. Nos anos 60 fui considerado um inimigo de Deus e da pátria, um bandido terrível. Pois bem, hoje eu já não seria mais considerado inimigo de Deus. Você veja o que é a história. Hoje diriam apenas que sou um saudosista das esquerdas. O discurso da classe dominante mudou, mas ela continua não concordando, de jeito nenhum, que as massas populares se tornem lúcidas. (FREIRE, 1994, [s. p.]).

Resistindo em nossos dias, aprendemos e continuamos aprendendo que Paulo Freire foi um homem simples e humilde que conseguiu olhar a realidade dos trabalhadores rurais, domésticas, pedreiros e outros trabalhadores da região de Angicos, povoado do sertão brasileiro, no Rio Grande do Norte, e neles percebeu um caminho para a construção do conhecimento a partir das palavras geradoras. Foram 45 dias de dedicação, amorosidade, alteridade, diálogo e nascia uma pedagogia fora dos padrões tradicionais do ensino-aprendizagem, porém de transformação.

Transformou um grupo de 300 analfabetos que foram capacitados a ler e escrever. Transformou Angicos, que além de estar na gênese da pedagogia freiriana, também abriu possibilidades ao emprego, aos direitos de cidadãos, como no voto. Transformou e interpelou uma metodologia engessada, curricular e de transmissão de conhecimento, para um método de aprendizagem a partir das palavras geradoras, com um olhar crítico para o mundo. E transformou a realidade da educação brasileira, pois o método de Paulo Freire inspirou o Programa Nacional de Alfabetização (PNA) e, até hoje, é tido como patrono da educação no Brasil.

A transformação que Paulo Freire realizou em Angicos, e que depois se espalhou pelo mundo, consistiu em fazer florescer o pensamento crítico em torno da realidade dos protagonistas deste processo de aprendizagem. Nas palavras de Ana Maria Araújo Freire, viúva de Paulo Freire e guardiã da obra e legado:
6 Extraído da reportagem "Porque as ideias de Paulo Freire ainda incomodam?", publicada no Jornal Folha de São Paulo, em 31 de outubro de 2017. 
Ele ensinava a pensar. Não quero uma alfabetização mecânica - ele dizia -, eu quero, o povo precisa, o Brasil precisa de uma alfabetização conscientizadora. Pensar é muito perigoso. Sempre foi, na história do mundo, e aqui no Brasil há muito forte essa questão contra aqueles que pensam. Pensar é perigoso para as pessoas autoritárias. O autoritário quer que, ao dizer "faça isso!", a pessoa faça, não pense nem se é bom ou é ruim. Para quem, e por que vai fazer aquilo. (ARAÚJO FREIRE, 2019, [s. p.]).

Passadas mais de cinco décadas, o legado de Paulo Freire permanece contemporâneo e está latente para além das fronteiras brasileiras. Dos limites do sertão brasileiro, desponta um novo olhar sob a educação que olha o mundo, a cultura e a realidade social.

Paulo Freire estabeleceu um conjunto de valores que parte da realidade da vida de quem se coloca no caminho do conhecimento e abre o horizonte que ultrapassa a própria realidade e é capaz de olhar com criticidade.

Opondo-se a uma educação conteudista e bancária, sua proposta é de que a educação seja capaz de humanizar, libertar dos processos de opressão e doutrinação:

É que, se os homens são estes seres da busca e se sua vocação ontológica é humanizar-se, podem, cedo ou tarde, perceber a contradição em que a "educação bancária" pretende mantê-los e engajar-se na luta por sua libertação. (FREIRE, 2011b, p. 86).

E o caminho proposto por Paulo Freire para interagir com o mundo e se libertar é o diálogo: "O diálogo é este encontro dos homens, mediatizados pelo mundo, para pronunciá-lo, não se esgotando, portanto, na relação eu-tu... o diálogo é uma exigência existencial" (FREIRE, 2011b, p. 109).

Mais que uma proposta à educação, Paulo Freire deixa um legado à existência humana. O seu olhar está voltado primeiramente para a pessoa, como ser em potência, capaz de ir além, superar-se e, a partir de sua autonomia, transformar sua realidade e consequentemente, voltar-se ao outro.

Paulo Freire e seu pensamento permanecem vivos na dedicação de cada homem e mulher que se faz "educador-educando", enfrentando as contrariedades e as dificuldades da educação atual. Que são capazes de ler a realidade das crianças, dos adolescentes, dos adultos e suas famílias: "Porque não discutir com os alunos a realidade concreta a que se deva associar a disciplina cujo conteúdo se ensina...?" (FREIRE, 2011b, p. 32).

Faz-se jus recordar a realidade do sertão brasileiro, dos povos ribeirinhos na imensa Amazônia, dos que 
caminham quilômetros, no Nordeste, para estudar e acreditam em um futuro promissor. As grandes metrópoles brasileiras permeadas de desafios, contradições e sofrimentos. Em meio a toda essa diversidade brasileira há muitos freirianos que acreditam na pessoa humana e ajudam essas pessoas, a partir da realidade, a estabelecer o diálogo, a criticidade e a transformação social:

Freire entrou para trabalhar nesse espaço, o que parece à primeira vista contraditório; no entanto foi lá, aprendendo com os trabalhadores urbanos, rurais e pescadores, mas sobretudo com as relações impostas pelo patronato ao operariado, que foi capaz de ir formulando um pensamento pedagógico com as marcas do diálogo, da criticidade e da transformação social. (FREIRE, 2015, p. 287).

Resgatar o legado de Paulo Freire é olhar com amorosidade a existência humana e o mundo, buscando a dignidade coletiva e fomentando a esperança que leva à justiça e ao compromisso de solidariedade com o outro:

Freire trabalha com a concretude da produção do sentido e do sentir amorosidade/amor como uma potencialidade e uma capacidade humana que remete a uma condição de finalidade existencial ético-cultural no mundo e com o mundo. Uma amorosidade partilhada que proporcione dignidade coletiva e utópicas esperanças em que a vida é referência para viver com justiça neste mundo. A amorosidade freiriana que percorre toda a sua obra e sua vida se materializa no afeto como compromisso com o outro, que se faz engravidado da solidariedade e da humildade. (FERNANDES, 2016 apud STRECK; REDIN; ZITKOSKI, 2016, p. 37).

Eixo central do pensamento freiriano, o diálogo é o caminho que se deve percorrer na superação das diferenças e das contrariedades. No diálogo se funda a relação educador-educando, e é pelo diálogo que se pode pronunciar o mundo: "A conquista implícita no diálogo é a do mundo pelos sujeitos dialógicos, não a de um pelo outro. Conquista do mundo para a libertação dos homens" (FREIRE, 2011b, p. 110).

Em tempos de diversidades, contrariedades e incompreensões, Paulo Freire propõe o diálogo como caminho de escuta e acolhimento:

Aceitar e respeitar a diferença é uma dessas virtudes sem o que a escuta não se pode dar (FREIRE, 1998, p. 136). Sem escuta não há diálogo, há monólogo; e este é terreno fértil para a imposição de valores, a invasão cultural e a dominação. (GUSTSACK, 2016, p. 119). 
Bem-aventurados os que resistem em tempos de incertezas, dialogam em uma atitude de abertura ao outro, sem impor-lhe, mas com alteridade. $O$ diálogo que constrói em coletividade, que olha o outro como par, sem distinção, sem discriminação, sem exclusão. Diálogo estabelecido na educação, na sociedade com os iguais e os opostos, buscando o horizonte do bem comum. Atitude que edifica, transforma, supera e congrega. Paulo Freire se faz presente neste diálogo com o outro e com o mundo.

As relações, o pronunciar o mundo, devem estar pautadas na criticidade. Toda transformação nasce a partir do olhar crítico. Nesse sentido, Paulo Freire impulsionou os trabalhadores de Angicos a olhar criticamente sua condição e sua realidade e os levou ao caminho da transformação.

A existência, porque humana, não pode ser muda, silenciosa, nem tampouco pode nutrir-se de falsas palavras, mas de palavras verdadeiras, com que os homens transformam o mundo. Existir, humanamente, é pronunciar o mundo, é modifica-lo. O mundo pronunciado, por sua vez, se volta problematizado aos sujeitos pronunciantes, a exigir deles novo pronunciar. (FREIRE, 2011b, p. 108).

Essa criticidade está sendo mal compreendida e, por sua vez, combatida em nossos dias. Passar do senso comum à criticidade é um caminho que urge ser percorrido: "A necessária promoção da ingenuidade à criticidade não pode ou não deve ser feita a distância de uma rigorosa formação ética [...]" (FREIRE, 2011b, p. 34). O legado de Paulo Freire alimenta o desejo de justiça social, quando se olha o mundo e se percebe o abismo entre as classes sociais. Quando se constata o desnivelamento do direito de igualdade.

O pensamento freiriano ajuda a pronunciar o mundo com um olhar ético que leva à transformação: "Não há palavra verdadeira que não seja práxis. Daí que dizer a palavra verdadeira seja transformar o mundo" (FREIRE, 2011b, p. 107).

Paulo Freire não publicou um livro que aborde de modo específico o tema da ética. No entanto, todo seu pensamento é permeado por um permanente rigor ético em defesa da dignidade humana. Sua opção humanista se manifesta com clareza na sua ética da libertação e da solidariedade que assume o compromisso de lutar pela dignidade do oprimido, do excluído e pela justiça global. É a partir da ética universal do ser que devemos pensar todas as relações dos humanos entre si e destes com a natureza e com a vida. (TROMBETTA; TROMBETTA, 2016. p. 166).

Por fim, não se pode negar a atualidade do pensamento freiriano, pois se trata de um projeto de existência 
humana. Então, como se pode "expurgar" uma proposta de vida? Como combater a doutrinação ideológica e o mesmo governo brasileiro deixar de investir em faculdades de filosofia e sociologia ${ }^{7}$, as quais aguçam o pronunciar o mundo e o pensar crítico? Não seria essa uma atitude contraditória?

\section{Presença atual de Paulo Freire nos Estados Unidos e na UCLA}

Apesar de ter falecido há mais de 22 anos, Freire continua sendo muito utilizado em todo o mundo nos dias atuais. Em estudo realizado por Oliveira e Santos (2018), foram mapeados Institutos, Cátedras, Grupos de pesquisas, na América Latina e nos Estados Unidos, onde o legado da educação de Paulo Freire está presente. O estudo identificou 84 institutos/grupos/ ações na América Latina e 11 nos EUA, os quais evidenciam a existência de um legado e a importância de estudos sobre a sua obra e de experiências educacionais de base freireana (OLIVEIRA; SANTOS, 2018).

Os conceitos de Freire da pedagogia crítica, da justiça social e do multiculturalismo foram disseminados por toda a América do Norte, e seu pensamento teve grande influência nos educadores americanos da atualidade, como Peter McLaren, Donaldo Macedo, Henry Giroux, Michael Apple e Carlos Alberto Torres.

De acordo com Oliveira e Santos (2018), o pensamento socioeducacional de Paulo Freire é projetado nos Estados Unidos em Institutos, Grupos de estudos, Escolas, Projetos e Programas, essencialmente vinculados às universidades. Assim, Paulo Freire nos Estados Unidos tem sido referência a práticas educacionais, principalmente em Universidades norte-americanas, e está presente em formações, eventos e publicações por meio de projetos educacionais e grupos de pesquisas (OLIVEIRA; SANTOS, 2018).

Uma destas universidades norte-americanas que acentua a presença de Freire é a Universidade da Califórnia em Los Angeles (UCLA), na qual além de ser largamente utilizado em suas disciplinas de curso, Freire tem um Instituto em sua referência.

O professor Peter McLaren, professor emérito da UCLA e renomado internacionalmente, tem na sua obra grande influência de Freire. Em uma entrevista cedida à revista IHU On-line, em 2007, McLaren comenta sobre a importância de Freire nos EUA. Quando perguntado sobre as contribuições de Freire nos EUA e para a pedagogia crítica, McLaren confirma esta importância:

Paulo Freire é, de longe, o mais importante educador crítico lido nos EUA. Seu trabalho é consistentemente adotado por estudantes em universidades, por professores do ensino fundamental e médio, por estudantes de
7 Jair Messias Bolsonaro em seu Twitter no dia 26 de abril de 2019. 
magistério e por membros de grupos de ação social e de novos movimentos sociais, ou seja, por grupos do setor não-formal [sic]. Seu trabalho é encontrado nas aulas, nas universidades, em estudos de alfabetização, na teologia, na pedagogia crítica, e através das ciências humanas. (IHU ON-LINE, 2007, [s. p.]).

Durante a entrevista McLaren também comentou sobre a situação de ser um professor que busca o socialismo e que isso assusta muita gente. Durante o governo Bush (2001 a 2009), disse ter sofrido ameaças e foi considerado o professor mais perigoso da UCLA. Foi acusado de ser comunista e fazer lavagem cerebral na juventude americana.

Por anos, grupos de direita de todas as tendências me marcaram por meu trabalho com o falecido Paulo Freire, meus escritos sobre Che Guevara, minhas análises humanistas-marxistas da sociedade capitalista, e pelo fato de eu ligar a pedagogia crítica com a luta pelo socialismo. Mas tenho tido sorte de até agora não haver tentativas de me silenciar por parte da administração da universidade. O que deixa a situação mais periclitante é que, agora, a administração de Bush tem o poder legal de punir seus críticos e oponentes, o que outras administrações não tinham [...]. Existem medidas (legais) introduzidas em nove estados para suprimir a liberdade acadêmica nas universidades. Críticos de direita atacam professores como eu, que seguem o exemplo de Freire, silenciosamente e dissimuladamente "doutrinando" estudantes com propaganda esquerdista. (IHU ON-LINE, 2007, [s. p.]).

Essa tentativa de silenciar se repete no governo atual no Brasil; contudo, não existe educação neutra e toda educação é política. A educação deve ir contra o que se chama de hegemonia de pensamento, ou o autoritarismo, seja de direita ou de esquerda. Freire (2011b, p. 106) argumenta que se encontra autoritarismo tanto na direita quanto na esquerda do espectro político, e é verdade que ambos os grupos podem ser reacionários de "forma idêntica" se eles "[...] se julgam os donos do conhecimento, o primeiro, do conhecimento revolucionário, o último, do conhecimento conservador" e, de acordo com McLaren (IHU ON-LINE, 2007, [s. p.]), "ambas as formas de autoritarismo são elitistas".

Para McLaren, Freire nos EUA tem um contexto atual, pois ele é um dos poucos que critica o sistema capitalista e as limitações causadas para a educação americana, por meio da educação autoritária e não democrática (IHU ON-LINE, 2007). O que se observa é que as ideias de Freire são levadas mais à frente no contexto mundial, no contexto 
social e obviamente trazendo novas perspectivas críticas aos sistemas capitalistas, em especial ao americano.

A UCLA é uma universidade pública do sistema estadual da Califórnia. Considerada uma das melhores universidades do mundo, foi fundada em 1919, e possui cerca de 25 mil estudantes de graduação e 11 mil de pós-graduação. Sua biblioteca central possui cerca de 8 milhões de livros, sendo a oitava maior dos Estados Unidos. Sua história confirma a qualidade, conquistando vários prêmios que referenciam esta qualidade, entre eles, 14 prêmios Nobel, 116 títulos da NCAA e mais medalhas olímpicas (261) do que a maioria dos países (UCLA, 2019).

Com um orçamento anual em torno de 6,33 bilhões de dólares, a UCLA oferece 125 cursos de graduação ofertados pela universidade e escolas profissionais, nas diversas áreas de conhecimento. Contudo, o impacto acadêmico na pós-graduação é ainda maior, na qual em seu ranking anual das principais escolas de pós-graduação, o relatório U.S News and World (2018) listou seis escolas profissionais da UCLA e programas de pós-graduação entre os cinco melhores dos EUA (UCLA, 2019). Entre eles, estão a escola de pós-graduação em educação da UCLA que foi nomeada como número 1 do ranking americano para a área de educação, demonstrando a qualidade, reputação e abrangência da educação de nível superior (UCLA, 2019). Estes rankings baseiam-se em opiniões de especialistas sobre a excelência do programa e em indicadores estatísticos que medem a qualidade do corpo docente, da pesquisa e dos alunos de um programa de pós-graduação.

Os Programas de mestrado e doutorado em educação da UCLA contam com 44 professores em tempo integral na equipe, com uma proporção de 8,5:1 de doutorandos equivalentes em tempo integral para docentes em período integral (UCLA, 2019a). A taxa de matrícula com as mensalidades tem o valor de US\$ 11.442 por ano (residentes no estado) e em período integral: US\$26.544 por ano (fora do estado).

A pesquisa é parte integrante do ensino de pós-graduação na Graduate School of Education \& Information Studies (GSE \& IS) da UCLA. O campus de Los Angeles abriga centros conceituados como o Centro Nacional de Pesquisa em Avaliação, Padrões de Teste para Alunos; o Instituto de Pesquisa em Educação Superior; e o Centro de Educação Internacional e Desenvolvimento.

Os alunos podem obter experiência na UCLA Lab School, uma escola de testes no campus que experimenta técnicas educacionais inovadoras para alunos da pré-escola até o sexto ano. A escola também opera a Escola Comunitária da UCLA, na qual os membros do corpo docente podem pesquisar e demonstrar novas práticas de educação para os alunos da pré-escola até os alunos do ensino médio. O GSE \& IS é especialmente conhecido por seus programas de treinamento para administradores de educação, formuladores de políticas educacionais e psicólogos para a educação (UCLA, 2019a). 
O Programa de pós-graduação em educação da UCLA é focado em equidade para escolas urbanas e é reconhecido como líder no estudo da educação urbana e no desenvolvimento e apoio de professores e líderes escolares fortemente comprometidos com a justiça social. A escola de pós-graduação também abriga um renomado centro de inovação em métodos de pesquisa e avaliação. Os membros do corpo docente estão profundamente engajados em questões de raça e pobreza e seu impacto nas oportunidades educacionais no ensino fundamental e superior.

O Departamento de Educação da UCLA oferece vários graus em programas rigorosos e interdisciplinares em educação que fornecem flexibilidade para um corpo estudantil diversificado. $\mathrm{O}$ departamento oferece mestrado e doutorado acadêmico e profissional (M.A. e M.Ed) e doutorado (Ed.D. e Ph.D.) nas áreas do Ensino Superior, Desenvolvimento Humano e Psicologia, Metodologia de Pesquisa Social, Ciências Sociais e Educação Comparada, Escolaridade Urbana, Graus Profissionais em Educação, Assuntos Estudantis, Instituto de Liderança de Diretores de Escola, Programa de Formação de Professores, Programa de Liderança Educacional, Certificados em Metodologia Quantitativa Avançada em Pesquisa Educacional e Estudos de Educação de Menores (UCLA, 2019a).

O Programa de Pós-graduação em Educação da UCLA oferece dois programas, educação e estudos da informação, e 16 Centros de Pesquisa em Educação. Um destes Centros de Pesquisa é o Instituto Paulo Freire (Paulo Freire Institute - PFI). Paulo Freire visitou várias vezes a UCLA, em especial nos anos 1980 e 1990, e esse Instituto foi criado 1991, com a presença de Paulo Freire, pelo professor da UCLA, Carlos Alberto Torres e que atua ainda hoje como seu diretor. Torres é um dos principais biógrafos de Paulo Freire e cofundador da Rede Internacional do Instituto Paulo Freire, que inclui colegas e instituições em mais de 90 países da América do Norte, América do Sul e Europa.

O PFI procura reunir estudiosos e críticos do trabalho de Freire em diálogo permanente para promover o avanço de novas teorias e intervenções concretas no mundo real. $\mathrm{O}$ instituto tem a missão de propagar as ideias de Freire, oferecendo pesquisas que são publicadas em formato de livros e artigos, ou ainda, na difusão dos ideais de Freire em conferências e simpósios. O PFI oferece ainda cursos de verão para professores e alunos internos e externos da graduação e da pós-graduação, em assuntos como: Questões Emergentes em Sociologia da Educação: Política e Educação e Tópicos Especiais em Educação Comparada: A Dialética do Global e do Local, todos sob a ótica freireana.

O programa de graduação e de pós-graduação em educação da UCLA oferece inúmeras disciplinas na área com os principais filósofos e pensadores da educação desde Platão até Foucault. Contudo, Freire aparece de forma única dentro da ementa de duas disciplinas, o que não acontece com outros filósofos e pensadores. 
A disciplina de graduação, "207 - Política de Educação", de acordo com Manual do estudante do programa "Social Sciences and Comparative Education (SSCE) 20182019 Handbook, 2019” (UCLA, 2019c, [s. p.], tradução nossa). tem em seu ementário:

Dimensões políticas das instituições de ensino como organizações. Relações entre instituições de ensino e instituiçõos políticas na sociedade. Teoria política como fundamento para análise de políticas públicas; grupos de interesse na formação e implementação de políticas educacionais; e focar na pedagogia freireiana.

Outra disciplina, mas de pós-graduação, que é específica em Freire, chamada de “295 - Freire”. É um seminário no qual o aluno precisa ter o conhecimento prévio do trabalho de Freire. Tal disciplina tem como ementa:

Análise da produção intelectual de Paulo Freire vinculada ao contexto social em que ocorreu. Estudo de sua vida e obra em cinco fases: Experiência Brasileira (1921 a 1964); Experiência Chilena, onde publicou Educação como Prática de Liberdade e Pedagogia do Oprimido, bem como outras obras menos conhecidas, dedicando também a maior parte desse período à pesquisa empírica em alfabetização (1964 a 1969); seu trabalho em Harvard e, em seguida, no Conselho Mundial de Igrejas em Genebra (1970 a 1980), incluindo sua consultoria aos governos revolucionários pós-coloniais na África; seu retorno ao Brasil e seu trabalho como Secretário de Educação em São Paulo (1989 a 1992); e suas viagens globais de 1980 até sua morte em 1997. Foco no trabalho deixado incompleto antes de sua morte (incluindo ecopedagogia e escolas de cidadãos) e, por implicação, suas análises, críticas e impacto no mundo, sua metodologia de palavra geradora e comparações com outros referentes teóricos. (UCLA, 2019c, [s. p.], tradução nossa).

Na UCLA, as ideias freireanas são ressignificadas na totalidade da teoria temporal crítica, no contexto social da educação, na política organizacional, na educação internacional e urbana, com profunda familiaridade com as questões interculturais dos EUA e da América Latina. Como se observa, Freire está presente, não apenas na UCLA ou no contexto norte-americano, mas em várias partes do mundo onde, por meio dos institutos e disciplinas, o legado de Freire é homenageado, promovendo estudos que aplicam, ampliam, criticam e reinventam a pedagogia freireana. 


\section{Considerações finais}

Como se constata, ressurge no Brasil uma onda ultraconservadora que desconhece, ou ao menos, tenta desqualificar e combater um legado ilibado deixado por Paulo Freire. Ao mesmo tempo, resistem e ressurgem, também, em todos os cantos do Brasil, e do mundo, pensadores que mantêm atual o legado de Paulo Freire. E estes são sinais de esperança em nossos dias.

Freire apresenta uma ideia de justiça social que se encaixa com os conceitos essenciais do significado de democracia. Talvez seja devido a isso que Freire seja perseguido em sistemas os quais o capitalismo é proeminente, como nos EUA e no Brasil. O autoritarismo prevalece sobre a democracia em ambos os países, com consequência na educação, onde o aluno é apenas objeto da educação e não sujeito da própria construção.

A presença de Freire é marcante na UCLA, cujo programa de pós-graduação é considerado o primeiro em qualidade nos EUA. Foi criado, na UCLA, o Instituto Paulo Freire para difundir suas ideias. O programa oferece disciplinas em Freire para os seus alunos. Em sua matriz de disciplinas, nenhum outro educador tem disciplinas específicas, como acontece com Freire, o que demonstra a abrangência de Freire na instituição. Não podemos afirmar que o Programa é número 1 dos EUA devido a Freire, mas podemos considerar que sua obra é fator determinante nas discussões de formação de educadores da UCLA.

Podemos confirmar, ainda, que alguns dos mais proeminentes professores da atualidade como Peter McLaren e Carlos Alberto Torres, atuam na UCLA e divulgam o pensamento freireano em suas pesquisas e discussões.

São inúmeros freirianos dispostos a contrariar o sistema e as classes dominantes, e que transformam a educação e o mundo por acreditarem na existência humana, na sua capacidade de superação e por pronunciarem um mundo solidário que promova a dignidade humana, sendo contrário ao fatalismo, como disse Freire (2000, p. 61):

O sonho de um mundo melhor nasce das entranhas do seu contrário. Por isso corremos o risco tanto de idealizarmos o mundo melhor, desgarrando-nos do nosso concreto, quanto de demasiado 'aderidos' ao mundo concreto, submergirmo-nos no imobilismo fatalista.

Estes freirianos estão nas escolas, nas famílias, na religião, nas instituições, sozinhos ou em coletividade, plantando amorosidade, diálogo, alteridade, solidariedade, criticidade e vendo florescer milhares de Paulos Freires que acreditam na pessoa humana e sua capacidade de transcender, na contramão de qualquer forma de negar, expurgar ou minimizar este legado, afinal podemos ser contra ou a favor de Freire, mas nunca sem Freire. 


\section{Referências}

ARAÚJO FREIRE, Ana Maria. Tumatéia, 18 abr. 2019. Disponível em: https://tutameia.jor.br/pensar-e-muito-perigoso-diz-viuva-de-paulo-freire/. Acesso em: 14 maio 2019.

BARTLETT, Lesley. Paulo Freire and Peace Education. 2008. Disponível em: https://www.tc.columbia.edu/ epe/epe-entries/Bartlett_ch5_22febo8.pdf. Acesso em: 16 abr. 2019.

BECK, Caio. Método Paulo Freire de alfabetização. Andragogia Brasil, 2016. Disponível em: https://andragogiabrasil.com.br/metodo-paulo-freire-de-alfabetizacao/. Acesso em: 18 abr. 2019.

CALÇADE, Paula. Na mira de Bolsonaro, Paulo Freire não está no currículo, mas é referência em escolas. Folha de S. Paulo, 25 out. 2018. Disponível em: https://www1.folha.uol.com.br/educacao/2018/10/na-mira-de-bolsonaro-paulo-freire-nao-esta-no-curriculo-mas-e-referencia-em-escolas.shtml. Acesso em: 23 abr. 2019.

FEITOSA, Sonia Couto Souza; GADOTTI, Moacir. Método Paulo Freire: princípios e práticas de uma concepção popular de educação. São Paulo: Universidade de São Paulo, 1999 .

FREIRE, Paulo. A importância do ato de ler: em três artigos que se completam. Cortez: São Paulo, 1989.

FREIRE, Paulo. Entrevista. Folha deS. Paulo, 29 maio 1994.

FREIRE, Paulo. Pedagogia da indignação. São Paulo: Editora UNESP, 2000.

FREIRE, Paulo. Pedagogia da autonomia: saberes necessários à prática educativa. Paz e Terra: Rio de Janeiro, 2011a.

FREIRE, Paulo. Pedagogia do oprimido. 50. ed. Paz e Terra: Rio de Janeiro, 2011b.

FREIRE, Paulo. Pedagogia da esperança: um reencontro com a pedagogia do oprimido. 22. ed. Paz e Terra: São Paulo, 2015.

GUSTSACK, Felipe. Diferença. In: STRECK, Danilo Romeu; REDIN, Euclides; ZITKOSKI, Jaime José. Dicionário Paulo Freire. 3. ed. Autêntica editora: Belo Horizonte, 2016. p. 119.

GADOTTI, Moacir. A escola e o professor: Paulo Freire e a paixão de ensinar 1. ed. São Paulo: Publisher Brasil, 2007. 
HADDAD, Sérgio. Ação Educativa, 15 abr. 2019. Disponível em: http://acaoeducativa.org.br/blog/2019/04/15/ por-que-o-brasil-de-olavo-e-bolsonaro-ve-em-paulo-freire-um-inimigo/. Acesso em: 14 maio 2019.

IHU ON-LINE. Paulo Freire é o mais importante educador crítico lido nos EUA. IHU Online, $n$. 223, 11 jun. 2007. Disponível em: http://www.ihuonline.unisinos.br/index.php?option $=$ com_content\&\%20 view $=$ article\&id $=1025 \&$ secao $=223$. Acesso em: 20 abr. 2019 .

INSTITUTO PAULO FREIRE. Títulos, prêmios e homenagens que Paulo Freire recebeu por todo o mundo. 2019. Disponível em http://www.projetomemoria.art.br/PauloFreire/biografia/o9_biografia_homenagens.html. Acesso em: 21 abr. 2019.

NORONHA, Maria Izabel. Bolsonaro quer exilar Paulo Freire de novo. Se deixarmos. Rede Brasil Atual, 7 jan. 2019. Disponível em: https://www.redebrasilatual.com.br/blogs/ blog-na-rede/2019/o1/bolsonaro-quer-exilar-paulo-freire-de-novo-se-deixarmos. Acesso em: 23 abr. 2019.

OLIVEIRA, Ivanilde Apoluceno de; SANTOS, Tânia Regina Lobato dos Santos. Paulo Freire na América Latina e nos Estados Unidos: Cátedras e Grupos de Pesquisas. Revista Educação em Questão, Natal, v. 56, n. 48, p. 106-139, abr./jun. 2018.

PINA, Rute. Por que as ideias de Paulo Freire ainda incomodam? Brasil de Fato, 31 out. 2017. Disponível em: https://www.brasildefato.com.br/2017/10/31/por-que-as-ideias-de-paulo-freire-ainda-incomodam/. Acesso em: 14 maio 2019.

SANTIAGO, Eliete; BATISTA NETO, José. A pesquisa em educação fundamentada em Paulo Freire e as contribuições de seus referenciais para a formação de professores e a prática pedagógica. Revista e-Curriculum 2016, São Paulo, v. 14, n. 1, jan./mar. 2016. Disponível em: http:// www.redalyc.org/articulo.oa?id=76645155009. Acesso em: 10 abr. 2019.

SAUL, Ana Maria. Paulo freire na atualidade: legado e reinvenção. Revista e-curriculum, São Paulo, v. 14, n. 1, p. 9-34, jan./mar. 2016.

STRECK, Danilo Romeu, REDIN, Euclides, ZITKOSKI, Jaime José. Dicionário Paulo Freire. 3. ed. Autêntica editora: Belo Horizonte, 2016.

TROMBETTA, Sérgio; TROMBETTA, Luís Carlos. Ética. In: STRECK, Danilo Romeu; REDIN, Euclides; ZITKOSKI, Jaime José. Dicionário Paulo Freire. 3. ed. Autêntica editora: Belo Horizonte, 2016. p. 166. 
UNIVERSITY OF CALIFORNIA AT LOS ANGELES (UCLA). Graduate School of Education \& Information Studies (GSE \& IS). Admissions Overview. 2019a. Disponível em: https://gseis.ucla.edu/about/admissions/. Acesso em: 22 abr. 2019.

UNIVERSITY OF CALIFORNIA AT LOS ANGELES (UCLA). Overview. 2019b. Disponível em: http://www. ucla.edu/about/. Acesso em: 18 abr. 2019.

UNIVERSITY OF CALIFORNIA AT LOS ANGELES (UCLA). Social Sciences and Comparative Education (SSCE) 2018-2019 Handbook. 2019c. Disponível em: https://gseis.ucla.edu/media/SSCE-Handbook-2018-19. pdf?x63302. Acesso em: 11 abr. 2019.

VEIGA, Edson. Paulo Freire: como o legado do educador brasileiro é visto no exterior. BBC News Brasil, 12 jan. 2019. Disponível em: https://www.bbc.com/portuguese/ brasil-46830942. Acesso em: 19 abr. 2019.

Recebido em: 30/04/2019 Aprovado em: 09/10/2019 Publicado em: 20/12/2019 